\title{
EL DESPERTAR DE LA ARQUITECTURA MODERNA A ORILLAS DEL MEDITERRÁNEO: DEBATE Y CONTROVERSIA EN LOS CONTEXTOS DE ITALIA Y ESPAÑA
}

\author{
Pedro Miguel Jiménez Vicario, Micaela Antonucci
}

Arquitectos y teóricos españoles e italianos identificaron las nuevas tendencias arquitectónicas procedentes de Europa como elementos exógenos. Corrían los años 20 y se presentaba ante ellos el problema de encontrar razones locales que justificasen la adopción de las ideas y las formas de la nueva arquitectura. Para ello acudieron a la tradición que les era propia: la tradición mediterránea, clásica y vernácula. Dilucidar el papel que la arquitectura vernácula tuvo en un proceso de búsqueda común de un lenguaje arquitectónico propio es el principal objetivo de este artículo.

Palabras clave: modernidad, mediterraneidad, arquitectura moderna, arquitectura vernácula Keywords: modernity, mediterraneity, modern architecture, vernacular architecture

\section{INTRODUCCIÓN}

Revistas italianas y españolas del periodo de estudio considerado (1920-1940) contribuyeron a dar a conocer la situación arquitectónica internacional y, en paralelo, estimularon la difusión de la arquitectura moderna en sus respectivos contextos, convirtiéndose en un factor clave de su consolidación. Nos referimos a revistas como Architettura e Arti Decorative, fundada en 1921 y posteriormente renombrada Architettura (O rgano ufficiale del sindicato degli architetti) dirigida por M arcello Piacentini, Q uadrante de Pier M aria B ardi y M assimo B ontempelli (1933-1936), Casabella de Edoardo Persico y Giuseppe Pagano o D omus fundada en 1928 y dirigida por Gio Ponti hasta los años cuarenta. En España las obras de M ay, Taut, Gropius, Schumacher, etc., se publicaban en multitud de revistas entre las que se encontraban Arquitectura. Ó rgano de la Sociedad Central de Arquitectos, Cortijos y RascacieIos, D'A ci i d'Allá, La G aceta de les Arts, AC. D ocumentos de actividad contemporánea, etc.

Si consideramos la importancia que estos medios le otorgaron a la arquitectura vernácula mediterránea en el debate de la mediterraneidad en el caso italiano y en el seno del contexto español, podemos entender el impacto que esta cuestión tuvo en el acontecer arquitectónico independientemente de las posiciones de unas u otras revistas y las opiniones allí vertidas por sus articulistas.

En las últimas décadas ha aparecido una extensa bibliografía que aborda el desarrollo de Ia arquitectura moderna en el contexto mediterráneo como consecuencia de una actitud revisionista del Movimiento M oderno ${ }^{1}$. Teniendo en cuenta dichas obras y prestando especial atención a las fuentes documentales, nos proponemos como principal objetivo establecer el papel que ejerció la arquitectura vernácula mediterránea en la aparición y desarrollo de la arquitectura moderna en el contexto mediterráneo a través de un análisis comparado de los casos de España e Italia.

PRIMERAS REFERENCIAS A LA ARQUITECTURA VERNÁCULA MEDITERRÁNEA EN LOS CONTEXTOS DE ESPAÑA E ITALIA

La situación arquitectónica española a comienzos del siglo XX era cuanto menos confusa, debido a la coexistencia de diversos estilos y tendencias arquitectónicas. Se recurría a fuentes y motivos de lo más variopinto en la búsqueda de una arquitectura nacional: arquitecturas representativas de etapas anteriores de la historia de España, desde su pasado romano al neoclásico pasando por etapas intermedias como podían ser mudéjar o barroco. L a nostál gica imagen de lo nacional se fue sustituyendo por los estudios regionalistas que dieron lugar al florecimiento de una arquitectura caracterizada por multitud de clichés que
1. Autores como Benedetto Gravagnuolo, Antonio Pizza, Josep M. Rovira, Jaume Freixa, Jean Francoise Lejeune, Michelangelo Sabatino, entre otros, han investigado bajo distintos puntos de vista este episodio del Movimiento Moderno. Al respecto, véase por ejemplo LEJEUNE, J. F., Modern Architecture and the Mediterranean: Vernacular Dialogues and Contested Identities, Routledge, Londres, 2010; GRAVAGNUOLO, B., "From Schinkel to Le Corbusier. The Myth of the Mediterranean in Modern Architecture" en Lejeune, J. F. y Sabatino, M., eds., Modern Architecture and the Mediterranean. Vernacular Dialogues and Contested Identities, Routledge, Londres, 2010, pp. 15-40; PIZZA, A., "El Mediterráneo: creación y desarrollo de un mito" en Pizza, A., ed., J. LI. Sert y el Mediterráneo, Colegio de Arquitectos de Cataluña, Barcelona, 1997, pp. 12-45; ROVIRA, J. M., Urbanización en Punta Martinet, Ibiza, 1966-1971. Colegio de Arquitectos de Almería, Almería, 1996; FREIXA, J., “Josep Lluis Sert en América, etapas de una infidelidad" en Pizza, A., ed., J. LI. Sert y el Mediterráneo, Barcelona: Colegio de Arquitectos de Cataluña, 1997, pp. 80-101; LEJEUNE, J. F., "The modern and the mediterranean in Spain: Sert, Coderch, Bohigas, de la Sota, del Amo" en Lejeune, J. F. y Sabatino, M., eds., Modern architecture and the Mediterranean, vernacular dialogues and contested identities, Routledge, Londres, 2010, pp. 65-93; LEJEUNE, J. F. y SABATINO, M., "North versus South" en Modern architecture and the Mediterranean, vernacular dialogues and contested identities, Londres: Routledge, 2010, pp. 1-12. 


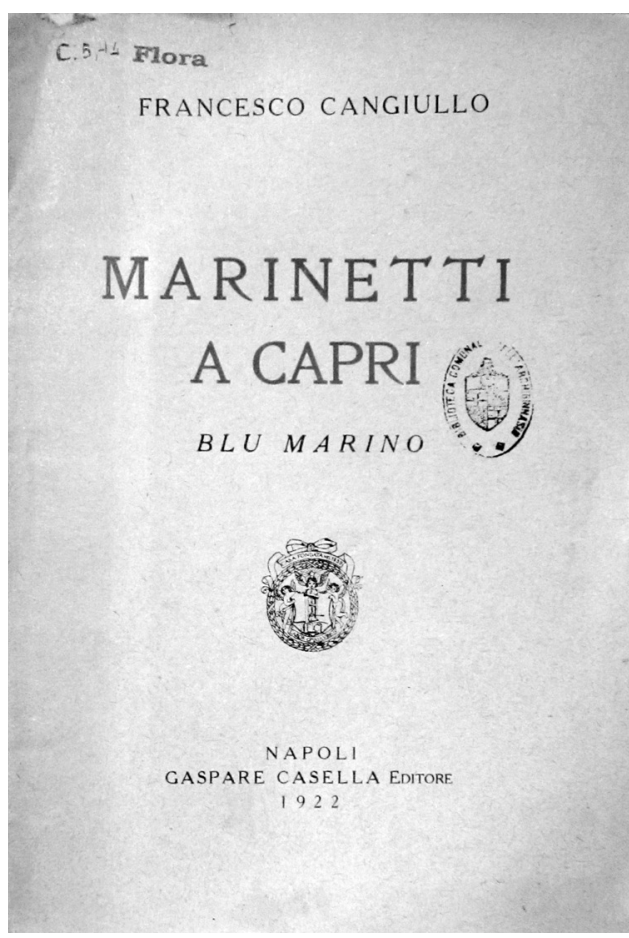

Fig. 1. Portada de la obra Marinetti a Capri en la que se narra la llegada del futurista a la isla de Capri en el verano de 1922, en CANGIULLO, F., Marinetti a Capri. Gaspare Casella, Nápoles, 1922.

2. TORRES BALBÁS, L., 1918. "Mientras labran los sillares", en Arquitectura: revista de la sociedad central de arquitectos 1918, 2, p. 33.

3. Una parte del poema dice así: "Menorca, tus casas blancas, las laberínticas paredes de toda la isla, pintada así de blanco, hacen más clara la esponja gris de la roca llana que sobresale del mar. La gente que vive allí busca la sombra de las casas bajas o la escuálida higuera que se enraíza en medio del pedregal" en PIJOAN, J., "De les Terres Velles", A.A.V.V., en Almanach dels Noucentistes, Joaquim Horta Impressor, Barcelona, 1911.

4. Nos refereimos a obras como Casa de la Palmera (1918) Viñas y olivos de Mont-Roig (1919) o La Masía (1921-1922) en MIRO, J., Museo Reina Sofía. [En línea] disponible en http://museoreinasofia.es/coleccion/obra/casa-palmera (8) [Accedido el día 8 de enero de 2015].

5. Véase SAMBRICIO, C., Madrid, vivienda y urbanismo: 1900-1960: de la "normalización de lo vernáculo" al Plan Regional, Akal, Madrid, 2004.

6. Para Navascués, la etapa central de la revalorización de la arquitectura popular podría establecerse entre el citado congreso y la conferencia de ingreso de 1929 en la Academia de Bellas Artes de San Fernando pronunciada por Teodoro de Anasagasti y titulada La arquitectura popular, en NAVASCUÉS PALACIO, P., Arquitectura española 1808-1914, Summa Artis, Historia General del Arte, vol. 35, Espasa Calpe, Madrid, 1993.

7. BOLETÍN DE LA SOCIEDAD CENTRAL DE ARQUITECTOS, "Conferencias en el Ateneo" en Boletín de la Sociedad Centra de Arquitectos, 1922, 127, pp. 3-4. daba lugar a lenguajes tan diferentes como el montañés o el sevillano. Este periodo en el que cabían las más variadas tendencias fue objeto de duras críticas por parte de arquitectos, artistas o intelectuales. Por ejemplo, L eopoldo Torres B al bás², director de la revista Arquitectura, se centró en combatir la idea tanto de una arquitectura española única "nacional" como el regional ismo, esforzándose entre 1919 y 1922 en encontrar el carácter del "estilo moderno":

"Propaguemos este sano casticismo abierto a todas las influencias, estudiando la arquitectura de nuestro país, recorriendo sus ciudades, pueblos y campos, analizando, midiendo, dibujando los viejos edificios de todos los tiempos, no solo los monumentales y más ricos, sino también, y tal vez con preferencia, los modestísimos que constituyen esa arquitectura cotidiana, popular y anónima, en cuyas formas se va perpetuando una secular tradición, y en la que podremos percibir mejor el espíritu constructivo de nuestra raza"

Las primeras referencias al M editerráneo se introdujeron a través del contexto catalán pos-modernista a través de Eugenio d'Ors desde 1911 mediante su obra G losari donde reivindicaba el ideal clasicista de "mediterraneidad" como respuesta a la tradición catalana. Ese mismo año J osé Pijoan elogiaba en 1911 en su poema "De les Terres Velles" la arquitectura blanca de $\mathrm{M}$ enorca ${ }^{3}$. Descripciones acerca de la integración de la arquitectura vernácula y el paisaje aparecen en la obra M editacions sobre la arquitectura de J. Folch i Torres publicada en 1916. En pintura cabe destacar algunas obras de J. Sunyer y de J. M iró4.

La arquitectura popular se convertía desde finales de la década de 1910 en un argumento de peso en congresos, conferencias y estudios que reivindicaban el concepto de la tradición en la discusión formal, el estudio de los materiales, la normalización constructiva - derivada en parte de la influencia del Deutscher Werkbund alemán-, en una actitud de compromiso con la realidad arquitectónica que vivía el país ${ }^{5}$. Es el caso de la conferencia pronunciada por Vicente L ampérez en el VII Congreso Nacional de A rquitectura celebrado en Sevilla en $1917^{6}$ y titulada Antecedentes históricos de la arquitectura rural en España o Arquitectura rústica y popular, celebrada en 1922 en el A teneo de M adrid. El lugar se convirtió en un importante enclave donde arquitectos como Gustavo Fernández B albuena ${ }^{7}$ y Pedro M uguruza ${ }^{8}$ también contribuyeron con sus conferencias a reforzar esta postura.

De este modo se producía en el panorama arquitectónico español un decantamiento hacia un renovado interés por la arquitectura popular - bien es cierto que presentada como una entre otras muchas opciones- y asumida por algunos de los más destacados protagonistas del debate arquitectónico de entonces como el único camino que permitía abandonar la encrucijada de estilos en que se había visto inmersa la arquitectura durante las dos primeras décadas del siglo XX.

Dirigiendo nuestra mirada a Italia, encontramos la antesala al racionalismo italiano en la época de Antonio Sant'Elia y los radicales manifiestos futuristas publicados en 1914, EI M essaggio en la revista Nuove Tendenze y II M anifesto dell' architettura futurista9. Ello posibilitó la existencia de una arquitectura avanzada e incluso logró cierto patrocinio para la misma en las décadas de 1920 y 1930. Las primeras afirmaciones vertidas sobre la arquitectura vernácula italiana hay que buscarlas, sorprendentemente, de la mano de los futuristas y su relación con la isla de Capri en el contexto del Ilamado "segundo futurismo" ${ }^{10}$. Como señala Ezio Godoli ${ }^{11}$, la situación asumida por el futurismo después de la Primera Guerra M undial se caracterizó por la desaparición de Sant'Elia y U mberto B occioni en la guerra y el interés de Filippo Tommaso $\mathrm{M}$ arinetti por mantener activo el movimiento futurista en todos los frentes artísticos, entre ell os la arquitectura. Fue en los años veinte cuando la isla de Capri se impuso como lugar del debate arquitectónico, asumiendo su arquitectura vernácula el papel de paradigma absoluto12. En 1922 se celebró el primer congreso del paisaje convocado por Edwin Cerio, donde los futuristas Virgilio M archi y F. T. M arinetti tuvieron una activa participación. El fundador del futurismo italiano defendía en su discurso titulado Lo stile pratico, la belleza de Capri y la simplicidad y funcionalidad de su arquitectura (Fig. 1).

Parecía como si la máquina, la velocidad y la modernidad se rindieran ante la funcionalidad sencilla y sincera de la arquitectura capresa. M arinetti lo narra asi ${ }^{13}$ :

“Capri, símbolo de la nueva Italia, resumen geológico y plástico de nuestra península y de nuestra raza [... ] Pero yo siento la isla plásticamente futurista, que rebosa infinita originalidad como si estuviera tallada 
por los arquitectos futuristas Sant'Elia, Virgilio M archi, pintada por Balla, Depero, Russolo, Prampolinia, cantada y musicalizada por Francesco Cangullo y da Casella"14

A quel año de 1922 Edwin Cerio escribió "L'A rchitettura minima nella Contrada delle Sirene" y también construyó varias viviendas en "estilo caprés", como fue el caso de la vivienda el "Rosai 0" 15 , A ntonio M araini escribía "L'architettura rustica alla cinquantennale romana"16 y Giuseppe Capponi "M otivi d'A rchitettura Ischiana" en $1927^{17}$. A demás de estos escritos es importante señalar el florecimiento de una serie de trabajos que, con una metodología sistematizada, también tuvieron como objetivo la arquitectura vernácula mediterránea en las dos primeras décadas del siglo XX.

\section{LOS DEBATES SOSTENIDOS EN EL SENO DE LAS VANGUARDIAS ESPAÑOLAS E ITALIANA: LO VERNÁCULO COMO OPCIÓN RACIONALISTA}

L a nueva arquitectura procedente de Europa y que llegaba a I talia y España tuvo su mayor acogida en contextos muy localizados del ámbito universitario. En las ciudades industriales del norte de Italia, como Turín y M ilán, aparecía el primer grupo racionalista y consistía en un pionero grupo de graduados del Politécnico de M ilán agrupados en el Ilamado Gruppo 7 - C.E. Rava, L. Figini, G. Pollini, G. Terragni, A. Libera, S. L arco y G. Frette-. Este impulso renovador se vio favorecido por la ausencia de una dirección concreta y "oficial" en materia de arquitectura debido al escaso tiempo que el fascismo llevaba en el poder. Corría el año 1926. En España, Carlos Flores ${ }^{18}$ establece un año antes, 1925, como una fecha tope que hace de charnela entre el desconcierto por las múltiples tendencias anteriores y la necesidad de renovación de los recién titulados en la Escuela de $M$ adrid ${ }^{19}$.

A esa generación de jóvenes arquitectos la llamó "generación de 1925" y estaba integrada por L uis Blanco-Soler, Rafael B ergamín, Casto Fernández-Shaw, M anuel Sánchez A rcas, Regino Borobio, J osé A zpiroz, L uis L acasa, Fernando García M ercadal, Carlos A rniches, M artín Domínguez, entre otros ${ }^{20}$. A unque el impulso a la arquitectura moderna española había comenzado definitivamente, todas las tendencias anteriores - regional ismo, historicismo, etc.- coexistieron durante la década de 1920 y pervivieron hasta la llegada de la Guerra Civil.

\section{EL CASO DE ESPAÑA}

La puesta en valor de la arquitectura popular como recurso local para la búsqueda de una arqui tectura moderna española se debió en parte a la labor de Teodoro de A nasagasti y L eopoldo Torres Balbás en Ia Escuela de A rquitectura de Madrid. A mbos maestros desarrollaban sus propios enfoques en lo referente a la formación de las Escuelas de A rquitectura en un ejercicio de integración entre la tradición y la modernidad. Para Teodoro de A nasagasti ${ }^{21}$ el profesor no debía oponerse a los libres estímulos que los estudiantes pudieran percibir y dibujar. Dichos estímulos podían proceder tanto de la arquitectura monumental como de la arquitectura popular y aunque no hace expresa referencia al dibujo de lo vernácul $0^{22}$, sí que ilustra el texto con apuntes propios de este tipo de arquitectura (Fig. 2).

Más explícito en relación a la arquitectura popular fue en su discurso de ingreso en la R eal A cademia de B ellas A rtes de San Fernando tan solo seis años después de la publicación de la Enseñanza de la Arquitectura ${ }^{23}$. En su conferencia afirmó que "Io pintoresco, distintivo y personal, lo netamente español" atraía a "Ios estudiosos extranjeros" e identificó la arquitectura popular localizada en los ambientes rurales como un producto genuinamente nacional, donde se manifestaba la inteligencia, la adaptación y el ingenio ${ }^{24}$.

Sus ideas regeneradoras para el Plan de estudios de la Escuela de A rquitectura fueron compartidas por Torres B albás ${ }^{25}$ quien transmitió a sus alumnos el interés por la arquitectura popular y de ello dejó constancia a través de una serie de conferencias y publicaciones aparecidas en la revista Arquitectura. Ó rgano de la Sociedad Central de Arquitectos. Es el caso de "U topías y divagaciones. Hacia la ciudad futura" ${ }^{26}$ y "Glosas a un Álbum de dibujos" 27 en el que recopiló el trabajo de García M ercadal y Rivas Eulate Documentos para un estudio de la arquitectura rural de España con dibujos de viviendas de arquitectura popular española (Fig. 3).

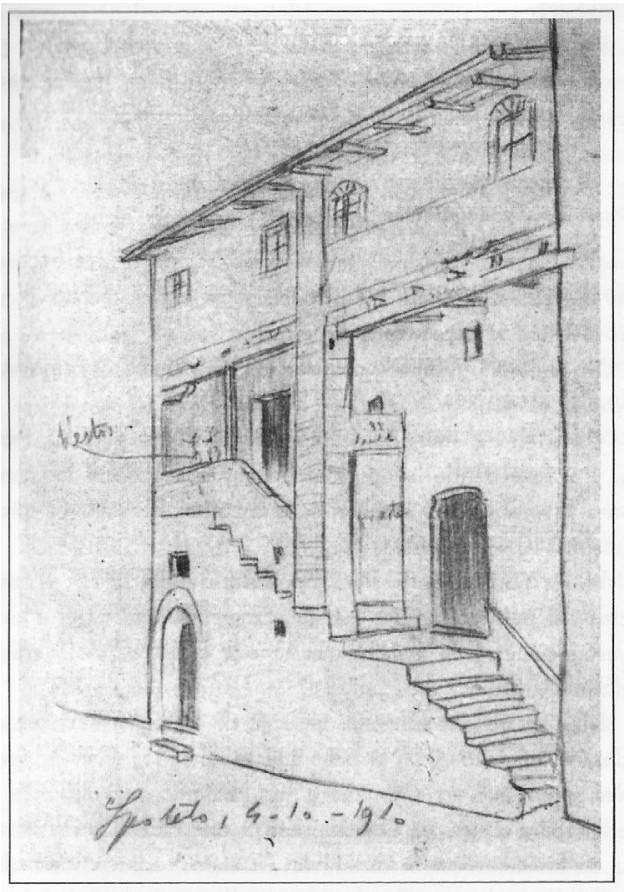

Fig. 2. Teodoro de Anasagasti, dibujo de 1910 de arquitectura vernácula de Spoleto, Italia, en ANASAGASTI, T. d., Enseñanza de la arquitectura. Cultura moderna técnico artística, Instituto Juan de Herrera, Madrid, $1^{\circ}$ ed. en 1923,1995, p. 114.

8. Ibid. pp. 3-4.

9. Véase CALVESI, M., Le due avanguardie, Laterza, Bari, 1971; CRISPOLTI, M., "La metropoli futurista", en E. Crispolti comp., Ricostruzione futurista dell' universo, catalogo della mostra, Torino, 1980, pp. 52-75; CRESTI, C., Futurismo $e$ architettura, Angelo Pontecorboli, Firenze, 2009.

10. En 1912 se publicó el artículo de arquitectura vernácula italiana de Aristide Baragiola, en BARAGIOLA, A., Sulla casa villereccia, en Congresso di etnografia italiana, Perugia, 1912. No obstante, las referencias a la arquitectura vernácula de la isla por parte de intelectuales centroeuropeos se remontan a mediados del siglo XIX. Véase JIMÉNEZ VICARIO, P. M., et al., "Dibujos de Capri. Entre el mito de Tiberio y el debate de la mediterraneidad", en EGA. Revista de expresión gráfica arquitectónica, 2014, 24, pp. 232-241.

11. GODOLI, E., Guide all'architettura moderna. // futurismo, Laterza, Bari, 1989

12. MANGONE, F., Capri e gli architetti, Massa, Nápoles, 2004.

13. Las traducciones que aparecen en el presente artículo han sido realizadas por los autores del mismo.

14. MARINETTI, F. T., I/ discorso di Marinetti al 'Convegno italiano per la difesa del paesaggio' Capri, Settembre de 1926 (i), Spes Salimbeni, Florencia, 1980.

15. CAPPONI, G., "Architettura ed Accademia a Capri. II 'Rosaio' di Edwin Cerio", en Architettura e Arti Decorative, 1929, 9, pp. 177-188.

16. MARAINI, A., "L'architettura rustica alla cinquantennale romana”, en Architettura e Arti Decorative, 1921-22, 4, pp. 379-385.

17. CAPPONI, G., "Motivi d'Architettura Ischiana”, en Ischia di altri tempi, Electa, Napoles, 1990. 

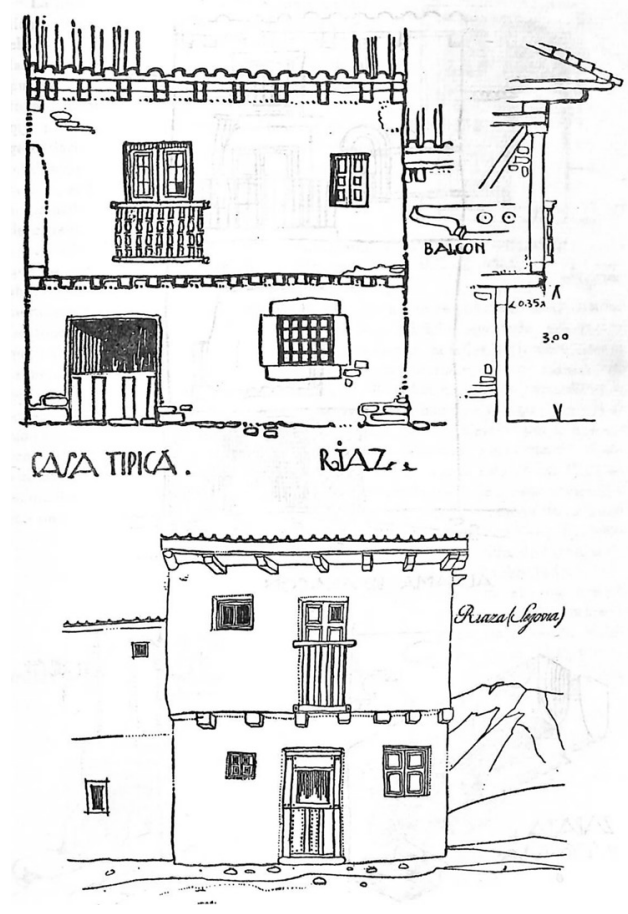

3
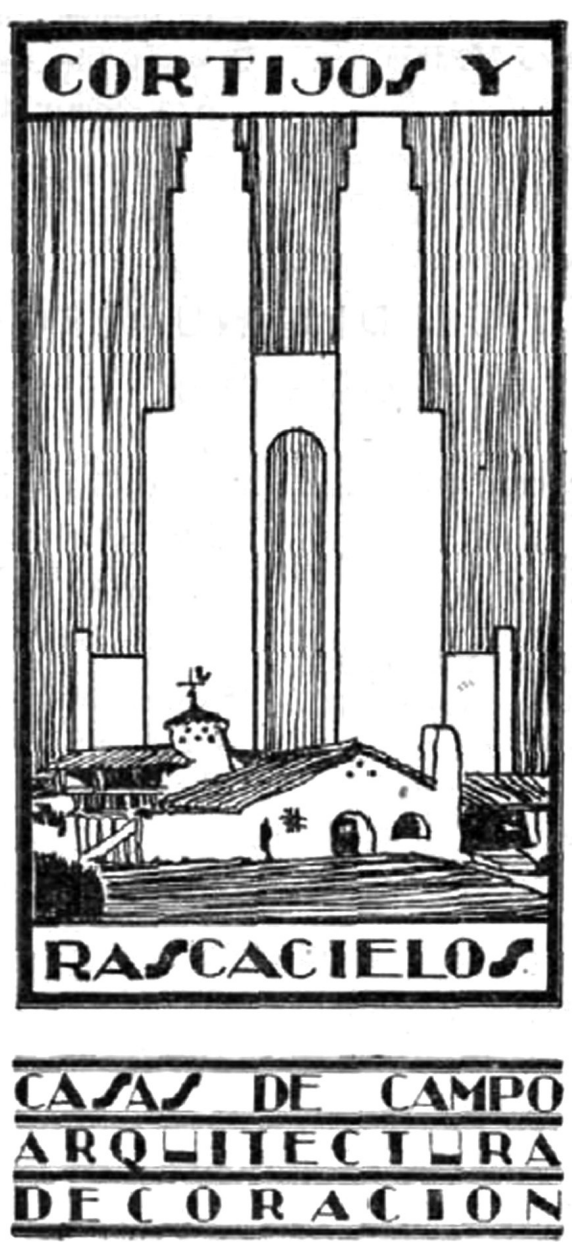

4
Sobre este trabajo Torres Balbás escribió:

“El álbum de dibujos de García M ercadal y Rivas Eulate, señala la acertada orientación de muchos de estos jóvenes arquitectos que comienzan a trabajar en la profesión. Hace años no se hubiera encontrado quien recorriese España copiando las obras humildes del arte popular [... ] H oy día los arquitectos jóvenes, ávidos de ver y conocer, recorren Europa, contrasta nuestra arquitectura con la de otros países, adquiriendo un concepto más amplio y certero de aquella" 28

Como consecuencia de la formación recibida en la Escuela M adrid, los recién titulados se preocuparon en la década de los años veinte por la arquitectura popul ar considerándola como un elemento válido para la renovación arquitectónica que permitiera situar la arquitectura española entre el eclecticismo del pasado y la nueva sensibilidad procedente de Europa ${ }^{29}$. Por ejemplo, para L uis L acasa ${ }^{30}$ la arquitectura popul ar debía jugar un papel importante en la utilización de los materiales disponibles; M anuel Sánchez A rcas ${ }^{31}$ pudo estudiar en Holanda la adaptación de los tipos tradicionales a la construcción moderna holandesa y establecer paralelismos con nuestra arquitectura popular desde un punto de vista plástico; Carlos A rniches y $M$ artín Domínguez ${ }^{32}$ hicieron una lectura de la modernidad desde la tradición de la arquitectura popular integrando en su arquitectura al gunos aspectos constructivos de la tradición y haciéndolos compatibles con algunos de los aspectos formales de una modernidad entendida de modo más bien superficial; para R afael B ergamín ${ }^{33}$ la arquitectura regionalista podía suponer un valor "positivo y cada vez mayor [... ] en el denominador de la fórmula del progreso de la arquitectura". L a dualidad moderno-vernácula la podemos analizar en C asto Fernández Shaw, quien bautizó la revista que fundó con el nombre de Cortijos y Rascacielos (Fig. 4); Sus posiciones eran similares a las de A ndrés Calzada ${ }^{34}$, Juan de Zabala ${ }^{35}$, A mos Salvador ${ }^{36}$ (1928) o J osé B orobio.

Especial atención merece el caso de Fernando García M ercadal. Como consecuencia de sus viajes por el M editerráneo y Centroeuropa pudo ir concretando una postura que manifestó a través de sus proyectos y artícul os publicados ${ }^{37}$. Todo ello, y posiblemente el cambio de actitud que experimentó L e Corbusier a finales de la década de los veinte, supuso que dejara de considerar a la arquitectura moderna como una exclusiva novedad de origen centroeurope $0^{38}$ para matizar que "Ias arquitecturas populares mediterráneas [... ] datan de varios sigl os antes del 'cubismo' arquitectónico de las modernas tendencias de 1923"39.

Con este planteamiento, García M ercadal atribuía a los iniciadores del movimiento moderno el único mérito de haber sabido leer la arquitectura que residía desde hacía muchos siglos en el M editerráneo y los val ores asociados a ella, en un momento en que las condiciones económicas y sociales de la época lo requerían:

"A Igunas de las características de esta arquitectura mediterránea como la simplicidad de formas, la ausencia de decoración, su cubismo, la intervención del color, su cubierta en terraza [... ] coinciden en absoluto con las de la arquitectura más avanzada, más en boga hoy en todas las naciones de Europa, en Francia, A lemania, Dinamarca, Checoslovaquia, A ustria, etc. [... ] y sería curioso también investigar sobre la posible influencia de estas construcciones mediterráneas sobre los iniciadores de esta tendencia"40

En Barcelona la situación no difería mucho. En un ambiente universitario propio de décadas anteriores, los alumnos observaban la nueva arquitectura procedente de Centroeuropa de forma autodidacta. Este hecho y los viajes que J osep L luis Sert realizó por el sur de España a finales de la década de 1920 con su compañero de clase de la Escuela de A rquitectura Germán Rodríguez A rias, le permitió establecer las primeras conexiones formal es entre ambas arquitecturas:

\footnotetext{
"M is amigos y yo en la Universidad de Barcelona estábamos muy influidos por la arquitectura popular. En seguida advertimos que la nueva arquitectura que nos llegaba en las revistas alemanas, escandinavas y holandesas se parecía a nuestros edificios de la costa mediterránea. Con sus cubiertas planas, como las de nuestras casas tradicionales más sencillas. Con volumetrías parecidas y simplicidad de medios. A sí que nos pareció que aquellas cosas no eran tan modernas para nosotros como las consideraban allá en el Norte" 41
}

De este modo encontraban las "raíces mediterráneas" de la arquitectura moderna que los situaba en una posición de ventaja respecto a la vanguardia europea al considerarse -como veremos en Italia- herederos legítimos de una tradición latina-mediterránea que había sido 


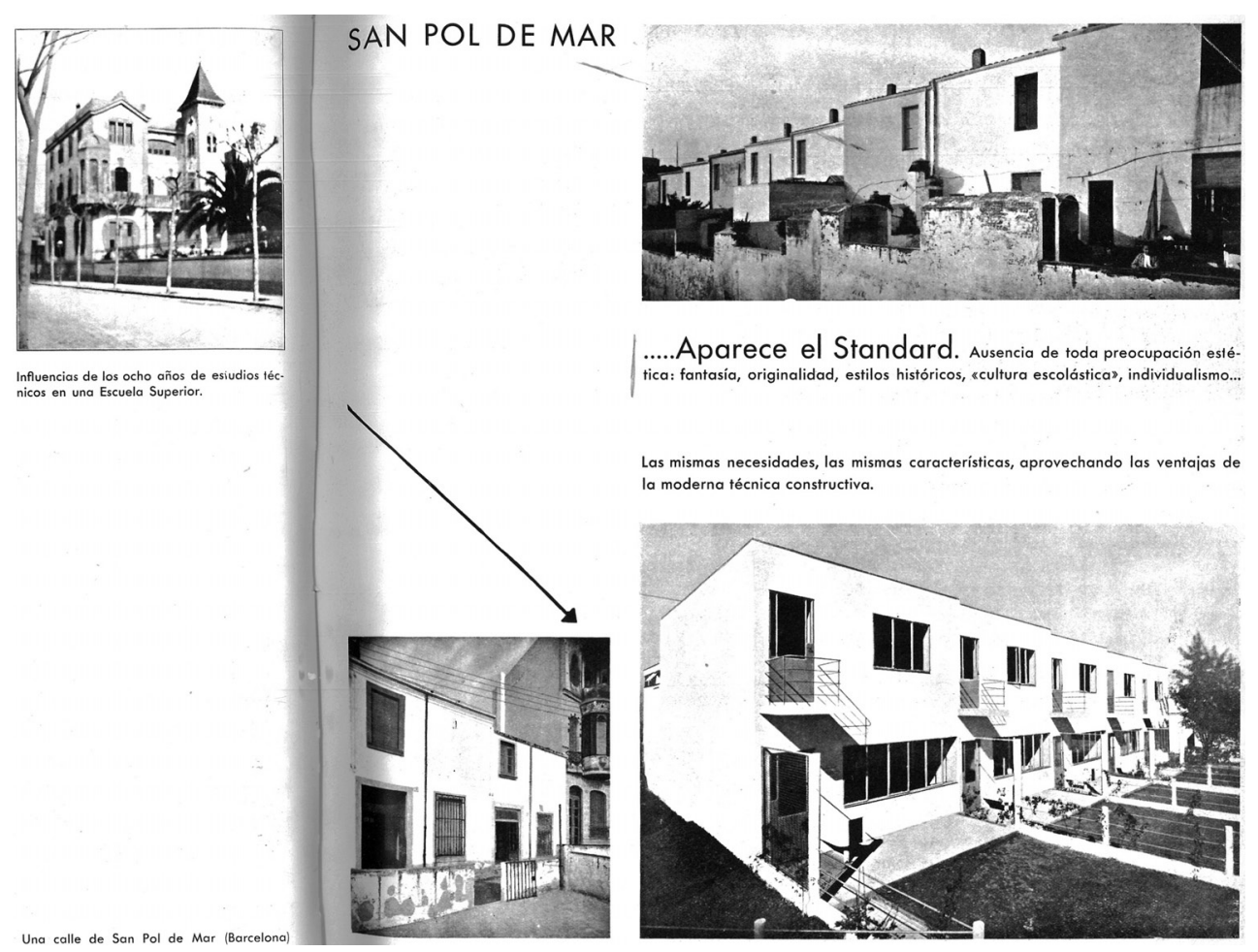

6

el punto de partida de la arquitectura racional ista ${ }^{42}$. $L$ a visita de $L$ e Corbusier a $B$ arcelona en 1928, su conferencia e impresiones sobre la arquitectura vernácula de la región les impulsó en el desarrollo de dicha idea (Fig. 5).

La adopción de la arquitectura vernácula mediterránea como fuente de estímulo y reflexión desde la que proponer una arquitectura moderna se fue consolidando progresivamente hasta llegar a un punto culminante con la formación del GATEPAC y la publicación de la revista AC. Documentos de actividad contemporánea. El manifiesto del GATEPAC, publicado en dicha revista exponían las tres ideas principales de su discurso: la primera estaba relacionada con el reconocimiento de una nueva arquitectura que debía responder a nuevas necesidades, en clara alusión a la arquitectura racionalista; la segunda idea consistía en la adaptación de dicha arquitectura a las condiciones particulares, afirmando que la arquitectura contemporánea debía estar de acuerdo con el carácter costumbrista y tradicional y alegando que la subsistencia de lo esencial residía en las "arquitecturas regionales" -entendidas como arquitectura vernácula-; la tercera idea lo constituía el rechazo al historicismo y la "arquitectura de imitaciones" (Fig. 6).

\section{EL CASO DE ITALIA}

Los escritos programáticos del Gruppo 7 aparecieron entre 1926 y 1927 con la publicación de cuatro ensayos en la revista La rassegna italiana. La evolución desde estos escritos, que no tenían el carácter de "manifiestos" propiamente dichos sino que más bien eran un análisis crítico de la situación arquitectónica establecida en Europa, muestra cómo la situación se fue haciendo más compleja y difícil situadas ante la opción de elegir una determinada tendencia debido a la incierta situación política y a la búsqueda de una posición original que caracterizara e identificara a la arquitectura italiana moderna. Su interpretación de la "racionalidad" osciló entre dos polos, por un lado, el vínculo con la arquitectura moderna europea y el funcionalismo como fuente de belleza y, en el otro extremo, el orden permanente y las características de la arquitectura clásica como recurso local mediterráneo. El término "mediterraneidad" aparecía en estos escritos con la misma frecuencia que otros vocablos que encarnaban la misma acepción, como "latinidad", "romanidad", "classicità", que suponían categorías unificadoras frente a la cultura extranjera y que constituían todo un repertorio lingüístico orquestado en sintonía con los principios mantenidos por el Régimen de M ussolini, al menos en los primeros años del Régimen ${ }^{43}$.

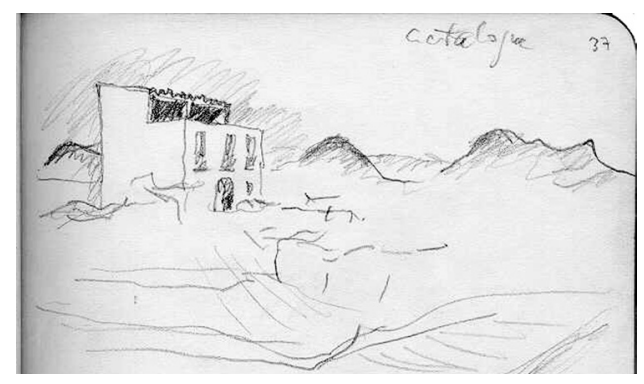

5

Fig. 3. García Mercadal y Rivas Eulate, apunte de una vivienda en Riaza, 1922, en TORRES BALBÁS, L., "Glosas a un álbum de dibujo", op. cit., p. 345.

Fig. 4. Dibujo de la portada del primer número de la revista Cortijos y Rascacielos, 1930.

Fig. 5. Le Corbusier, apunte de arquitectura vernácula durante su estancia en Cataluña en 1928 (doc. W1-694-001, Fondation Le Corbusier).

Fig. 6. Comparativa entre la arquitectura moderna de J.P. Oud para la Weissenhofsiedlung de Stuttgart, la arquitectura vernácula de San Pol de Mar y la arquitectura resultado de estudiar en una Escuela de Arquitectura, en AC. DOCUMENTOS DE ACTIVIDAD CONTEMPORÁNEA, "San Pol de Mar", en AC. Documentos de actividad contemporánea, 1, 1931. pp. 24-25.

18. FLORES, C., Arquitectura española contemporánea, Aguilar, Madrid, 1989, p. 93.

19. En Cataluña no aparecieron referencias a la polémica europea hasta 1929 salvo en personalidades aisladas como Folguera o Nicolau Rubio i Tuduri.

20. Véase DIÉGUEZ PATAO, S., La generación del 25, primera arquitectura moderna en Madrid, Cátedra, Madrid, 1997.

21. ANASAGASTI, T. d., Enseñanza de la arquitectura. Cultura moderna técnico artística, Instituto Juan de Herrera, Madrid, [1923] 1995, p. 110

22. La única referencia explícita al dibujo de la arquitectura popular lo escribe en el apartado de croquis del viajero donde menciona el dibujo del paisaje, la silueta de los pueblos, las construcciones rurales, etc.

23. El ingreso se celebró el 24 de marzo de 1929 y el título de su discurso fue Arquitectura popular.

24. ANASAGASTI, T. d., "Arquitectura popular" en Arquitectura popular. Discurso de D. Teodoro de Anasagasti y contestación del Excmo. Sr. D. Marceliano Santa María el día 24 de Marzo de 1929, Madrid, 1929, pp. 11.

25. TORRES BALBÁS, L., "La enseñanza de la arquitectura" en Arquitectura: Órgano de la Sociedad Central de Arquitectos, 1923, 46, pp. 36-40.

26. TORRES BALBÁS, L., "Utopías y divagaciones. Hacia la ciudad futura" en Arquitectura: Órgano de la Sociedad Central de Arquitectos, 24, 1920, pp. 104-107.

27. TORRES BALBÁS, L., "Glosas a un álbum de dibujo" en Arquitectura: Órgano de la Sociedad Central de Arquitectos, 40, 1922, pp. 338-348.

28. Ibid. p. 348 
Fig. 7. Plinio Marconi, dibujos de arquitectura vernácula de Capri y Anacapri, 1929, en MARCONI, P., op. cit., pp. 37-41.

29. Para conocer sus posturas respecto a la realidad arquitectónica que estaba viviendo el país, nos es de especial utilidad la encuesta promovida por García Mercadal y publicada en La Gaceta Literaria en 1928. La pregunta que más nos interesa de un total de seis fue la siguiente: "¿Las arquitecturas regionales pueden suponer un valor en la arquitectura del porvenir?" Dadas las posibles interpretaciones que puede suscitar el término "regionalismo", debemos analizar las respuestas teniendo en cuenta las dos posibles acepciones, "arquitectura regionalista" propiamente dicha o "arquitectura vernácula".

30. LACASA, L., "Encuesta sobre la nueva arquitectura" en La Gaceta Literaria, 1928, 32, p. 2.

31. SÁNCHEZ ARCAS, M., "Notas de un viaje por Holanda" en Arquitectura: órgano de la Sociedad Central de Arquitectos, 1926, 83, p. 110.

32. ARNICHES, C., DOMÍNGUEZ, M., "Encuesta sobre la nueva arquitectura" en La Gaceta Literaria, 1928, 32, p. 2

33. BERGAMIN, R., "Encuesta sobre la nueva arquitectura" en La Gaceta Literaria, 1928, 32, p. 6.

34. CALZADA, A., "Encuesta sobre la nueva arquitectura" en La Gaceta Literaria, 1928, 32, p. 2.

35. ZABALA, J. d., "Encuesta sobre la nueva arquitectura" en La Gaceta Literaria, 1928, 32, p. 3.

36. SALVADOR, A., "Encuesta sobre la nueva arquitectura" en La Gaceta Literaria, 1928, 32, p. 6.

37. Por ejemplo, véase GARCÍA MERCADAL, F., "Arquitec tura mediterránea", en Arquitectura: Órgano de la Sociedad Central de Arquitectos, 1926, 85, pp. 192-197; GARCÍA MERCADAL, F., La Casa popular en España, Espasa-Calpe, Bilbao, 1930; GARCÍA MERCADAL, F., Sobre el Mediterráneo sus litorales, pueblos, culturas (imágenes y recuerdos). Institución Fernando el Católico, Zaragoza, 1996. Esta última obra, título del discurso de ingreso en la Academia de San Fernando en 1980, fue ilustrada con los dibujos que García Mercadal realizó en 1924 en el golfo de Nápoles.

38. García Mercadal creía posible la fusión entre la tradición popular y la modernidad, observando los puntos en común entre la primera y las obras de Oud o Taut, en GIMÉNEZ CA BALLERO, E., "El arquitecto Mercadal". La Gaceta Literaria, 1928, 32, p. 5.

39. GARCÍA MERCADAL, F., La casa mediterránea: [exposición] Museo Español de Arte Contemporáneo, Madrid octubre-noviembre 1984, Ministerio de Cultura, Dirección General de Bellas Artes y Archivos, Madrid, 1984. p. 16

40. Ibid. p. 16

41. FREIXA, J., "Josep Lluis Sert en América, etapas de una infidelidad" en Pizza, A., ed., J. LI. Sert y el Mediterráneo, Colegio de Arquitectos de Cataluña, Barcelona, 1997, p. 98.

42. Véase ROVIRA, J. M., "Arquitectura: el mediterráneo es su cuna" en Pizza, A., ed., J. LI. Sert y el Mediterráneo, Colegio de Arquitectos de Cataluña, Barcelona, 1997, pp. 46-79.

43. Es significativo el texto de Gaetano Minucci y Adalberto Libera para la primera Exposición del MIAR de 1928: "No sotros italianos que dedicamos a este movimiento nuestras más vivas energías, sentimos que ésta es nuestra arquitectura porque nuestro es el legado romano de la potencia cons tructiva. Y profundamente racional, utilitario, industrial, ha sido la característica íntima de la arquitectura romana" en PATETTA, L., L'Architettura in Italia, 1919-1943. Le polemiche, Clup, Milán, 1972, p. 156.

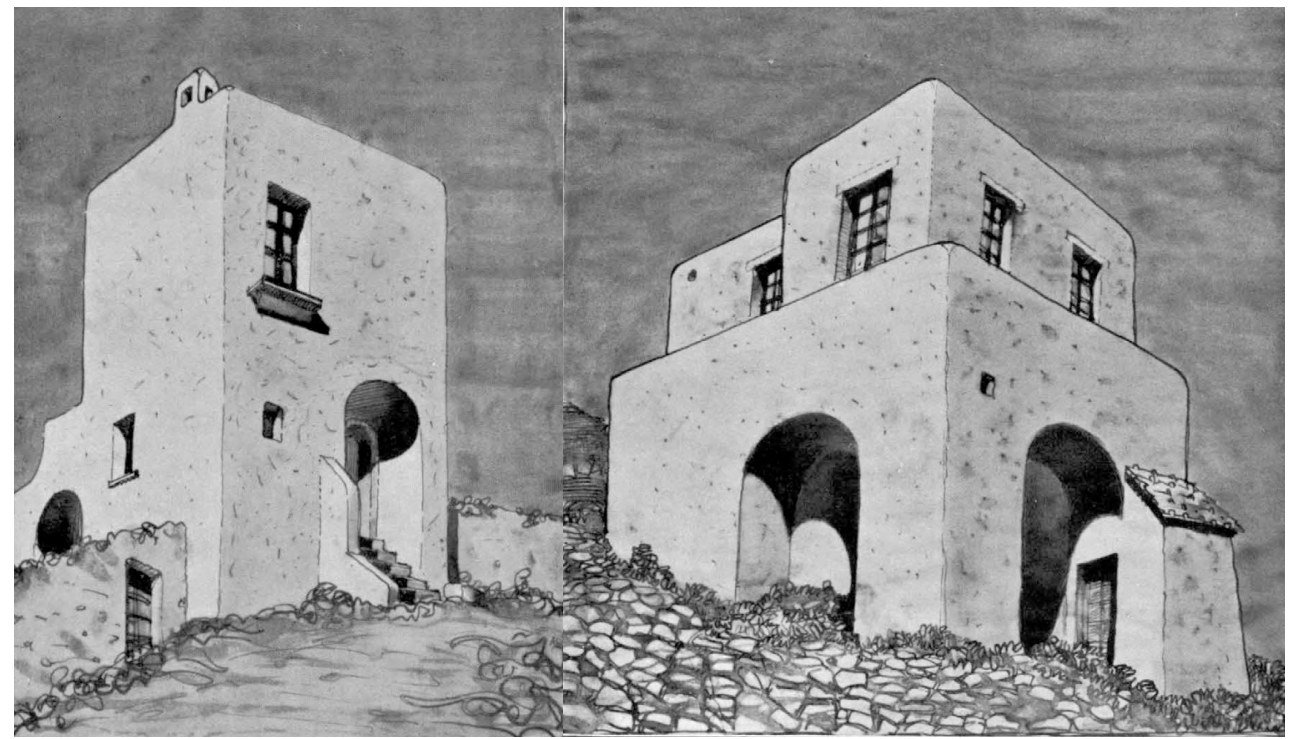

Junto a estas "opciones" aparecía otra visión, aquella de la arquitectura vernácula mediterránea y de la que el artículo de Plinio M arconi 44 titulado "A rchitetture minime mediterranee e architettura moderna" da buena fe. El autor reconocía que los arquitectos extranjeros habían precedido a los italianos en apreciar y valorar las bellas construcciones rústicas de la Italia meridional, por su aspecto pictórico y arquitectónico (Fig. 7).

Para él, la arquitectura mediterránea interesaba más que otras similares presentes en otros países porque "posee elementos extrañamente cercanos a la sensibilidad arquitectónica actual" 45 . El escrito de Plinio Marconi forma parte de los numerosos artículos sobre arquitectura vernácula mediterránea que se publicaron en la revista Architettura e Arti D ecorative en la década de los veinte. Es el caso del artículo de Roberto Pane ${ }^{46}$ titulado "Tipi d'A rchitettura rustica in Napoli e nei Campi Flegrei".

Entre los propios integrantes del Gruppo Sette pronto aparecieron las primeras diferencias sobre la adopción de una postura concreta. Carlo Enrico Rava, que había sido uno de los más activos integrantes e impulsor de varios de sus textos, pasó a ser uno de los mayores defensores de la idea de que la modernidad descansaba en la arquitectura popular de Italia, encendiendo así la mecha que prendió en 1931 el debate de la "mediterraneidad" en la revista D omus de Gio Ponti.

De este modo, Rava dejaba atrás las tesis de una mediterranedad que Ilevara hacia la romanidad para defender como ya lo había hecho antes Plinio M arconi, una búsqueda del racionalismo en la arquitectura vernácula italiana que permitiera justificar la adopción de la arquitectura moderna proveniente de los países centroeuropeos:

\begin{abstract}
"de nuestras costas líbicas a Capri, de la costa amalfitana a la ribera de Liguria, toda una arquitectura menor típicamente latina y nuestra, sin edad sin embargo nacionalísima, hecha de blancos, lisos, cubos y de grandes terrazas, mediterránea y solar, parece señalarnos la vía donde reencontrar nuestra más íntima esencia de italianos. Nuestra raza, nuestra cultura, nuestra civilización antigua y nuevísima, son mediterráneas: en este «espíritu mediterráneo» tendremos pues que buscar la característica de italianidad que todavía falta a nuestra joven arquitectura racional, porque un espíritu particular nos garantiza la reconquista de una primacía" 47 .
\end{abstract}

Esta fue la primera vez -enero de 1931- que Rava exponía tales ideas. Tras ese periodo, Rava ${ }^{48}$ dirigió su mirada a la gran lección de la italianidad tras un largo periodo de estudio en las fuentes esenciales que encontraba en "nuestra más espontánea y solar arquitectura menor (que los extranjeros antes que nosotros habían sabido comprender y val orizar también en el racionalismo)". De este modo, Rava interpretó la arquitectura vernácula de las costas del norte de África como evolución de la antigua casa romana, matizando así su lenguaje vernáculo para aproximarlo de nuevo a la idea de la "romanidad" que tanto gustaba al Régimen ${ }^{49}$ (Fig. 8). 


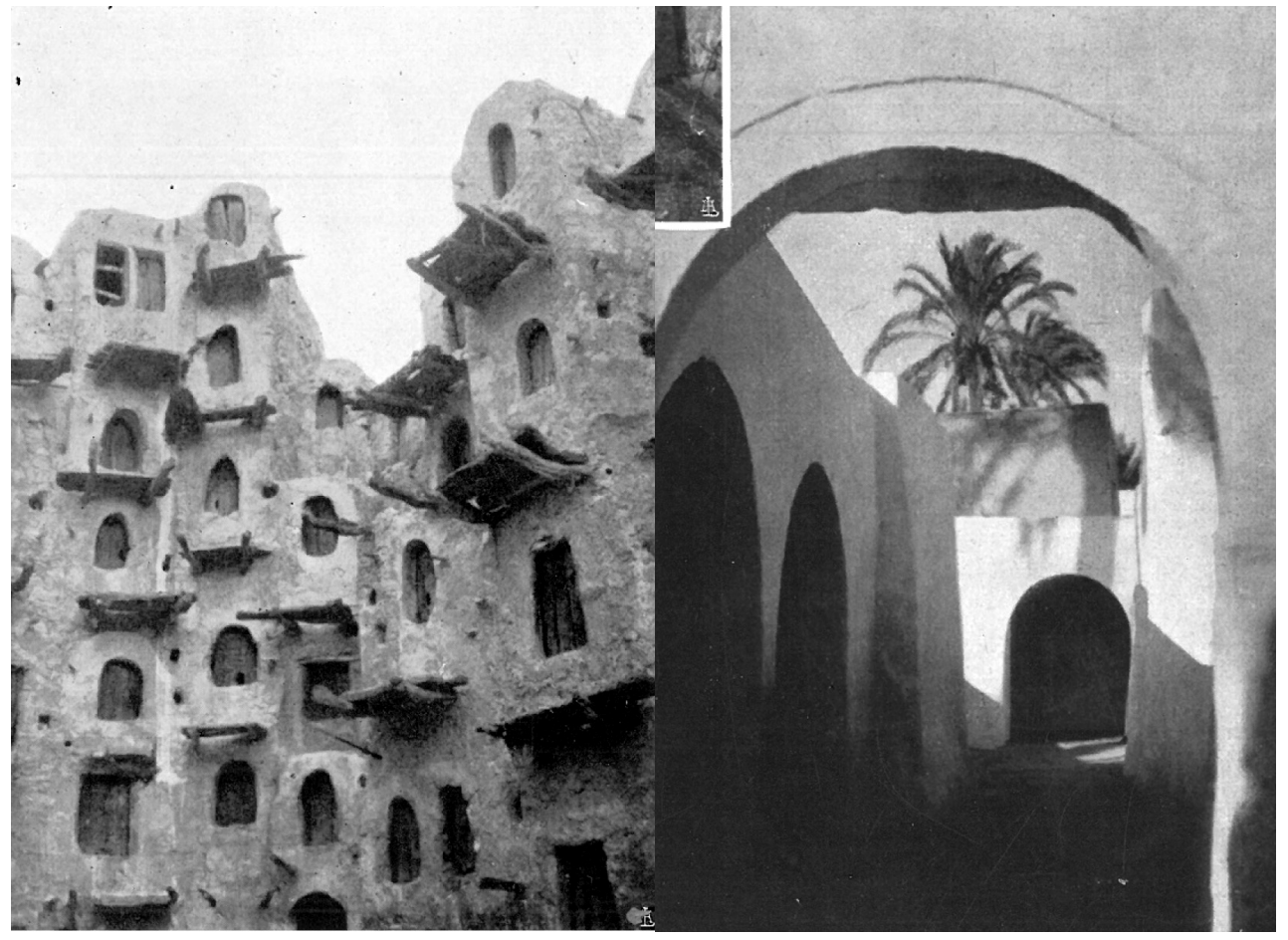

De modo similar a Rava, Giovanni M ichelucci ${ }^{50}$ pretendía mostrar como aquella arquitectura que decían "nórdica" o "alemana" tenía sus raíces en la arquitectura popular italiana (Fig. 9) a través de un ejercicio sencillo que consistía en sustituir las cubiertas inclinadas y los viejos enfoscados de arquitecturas vernáculas por cubiertas planas, barandillas metálicas y lisas superficies blancas. Por si quedara alguna duda, la revista Domus publicó junto al artículo de M ichelucci, otro artículo que mostraba imágenes de la WerkbundSiedlungen de Viena con proyectos de R. N eutra, A. L urcat, A. Loos u O. W lach entre otros.

Como le ocurriera a Rava, Giuseppe Pagano evolucionó hacia nuevas posiciones según iban sucediendo los hechos y debates en el devenir del racionalismo italiano. Su posición inicial la podemos situar en la línea de una arquitectura racional inspirada en una arquitectura clásica, por tanto en sintonía con la romanidad y la ideología que el fascismo propugnaba ${ }^{51}$

El punto de inflexión que experimentó la posición de Pagano lo apreciamos claramente en 1930 en su artículo titulado "A rchitettura moderna di venti secoli fa". Enaltecía la casa pompeyana ${ }^{52}$ en su condición de "maquinas edilicias" por su racionalismo y ausencias decorativas. De un modo muy ilustrativo comparó imágenes que presentaban claros parecidos formales entre arquitecturas racionalistas y la arquitectura de Pompeya. Podríamos decir que el artículo de Pagano ${ }^{53}$ de la casa pompeyana corresponde a una etapa intermedia entre las posturas de una mediterraneidad clásica y el giro que experimenta en torno a la vivienda vernácula, su posterior y principal línea de investigación en un momento importante para la política de "ruralización" del país que estaba llevando a cabo M ussolini ${ }^{54}$.

Para contraponer a la cultura oficial el patrimonio arquitectónico rural con el fin de ofrecer un elenco de tipos edificatorios como alternativa a aquéllos oficiales, expuso en 1936 junto a Guarniero Daniel La M ostra dell' architettura rurale nell bacino del M editerraneo en la VI Triennale di M ilano. En ella cel ebraban el valor estético y moral de la funcionalidad de la arquitectura a través de una extensa recopilación de imágenes de arquitecturas vernáculas procedentes de diversas partes de Italia y otras regiones mediterráneas, como muestra la leyenda del cartel de la muestra que exhibía el texto "Funcionalidad de la casa rural. Estudio de los arquitectos G. Pagano G. Daniel" 55 (Fig. 10).

La oscilación de posturas que observamos en Rava y Pagano, la podemos apreciar también en revistas como Quadrante, una revista de política y cultura próxima al fas-
Fig. 8. Fotografías de Rava del Castillo de Cabao y patio de casa de Euscir, en el Oasis de Suk-el-Giumaa, en RAVA, C.E. "Di un'architettura coloniale moderna" en Domus, 1931, 41, pp. 40-42

44. MARCONI, P., "Architetture minime mediterranee e architettura moderna" en Architettura e Arti Decorative, 1929, 1, pp. $27-44$

45. Ibid. p. 32

46. PANE, R., "Tipi di architettura rustica in Napoli e nei campi flegrei" en Architettura e Arti Decorative, 1928, 12, pp. 529-543.

47. RAVA, C.E., "Svolta pericolosa. Situazione dell'Italia di fronte al razionalismo europeo", en Domus, 1931, 37, p. 44 48. Ibid. p. 44

49. Orgulloso del camino emprendido, Rava mostró en su último artículo "Conclusione", un párrafo que motivó una importante polémica con Figini. La causa del desencuentro fue debido a la discusión acerca de la "autoría intelectual" del concepto "mediterraneidad", en RAVA, C.E., "Conclusione", en Domus, 47, 1931, pp. 34-40.

50. MICHELUCCI, G., "Fonti della moderna architettura italiana" en Domus, 1932, 56, pp. 460-461.

51. Este hecho era avalado por Pier Maria Bardi en Rapporto sull'Architettura (per Mussolini), en BARDI, P. M., Rapporto sull'Architettura (per Mussolini), Ed. Critica Fascista, Roma, 1931, p. 133.

52. El motivo de la casa pompeyana fue un recurso utilizado posteriormente en los modelos de casa colonial de Luigi Piccinato para la Triennale de 1933 y tuvo su reflejo también en "Una villa alla pompeiana" publicada por Gio Ponti en 1934; Cosenza haría lo propio en la Villa Cernio construida en Anacapri en los años sesenta.

53. PAGANO, G. "Architettura moderna di venti secoli fa" en La Casa Bella, 1931, 47, pp. 14-19.

54. A este respecto consideramos importantes los artículos publicados por G. Pagano en Casabella: PAGANO, G., "Architettura rurale in Italia" en Casabella, 1935, 96, pp. 16-23; PAGANO, G., "Case rurali"” en Casabella, 1935, 86, pp. 8-15; PAGANO, G., "Documenti di architettura rurale" in Casabella, 1935, 95, pp. 18-19.

55. El contexto en el que se desarrolló "La Mostra" es especialmente interesante: Luigi Cosenza realizaba por aquellos años junto con Bernard Rudolfsky la Villa Oro (1934-1937), la Casa Campanella en Positano (1937), Villa Savarese en Posillipo (1936). Roberto Pane publicaba Architettura rurale Campana y la revista Domus publicó proyectos de Gio Ponti que iban en la misma dirección que los de Pagano. Es el caso de "Una casa al mare", "Proposta di una casa al mare" y "Una piccola casa ideale", en PONTI, G., "Proposta di una casa al mare", en Domus, 1939, 79. 
Fig. 9. Michelucci G., operaciones formales sobre arquitectura vernácula italiana para demostrar el origen de la arquitectura moderna, en MICHELUCCI, G., op. cit. pp. 460-461.
56. FIGINI, L., "Realizazzioni del 'Gruppo 7'. Una Casa. Architetto: Giuseppe Terragni”, en Natura, 1930, 1, pp. 47-53.

57. DANESI, S., "Aporie dell'architettura italiana in periodo fascista -mediterraneità e purismo", en Danesi, S., Patetta, L., comp., II Razionalismo e l'architettura in Italia durante il fascismo, La Biennale di Venezia, Milán, 1988, p. 25.

58. PERESUTTI, E., "Architettura mediterránea" en Quadrante, 21, 1935, pp. 40-41.

59. Ibid. p. 40.
FONTI DELLA MODERNAARCHITETTURA ITALIANA

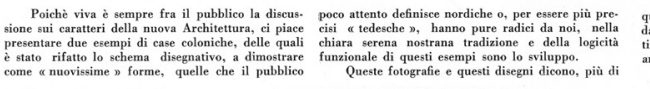

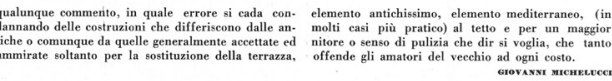
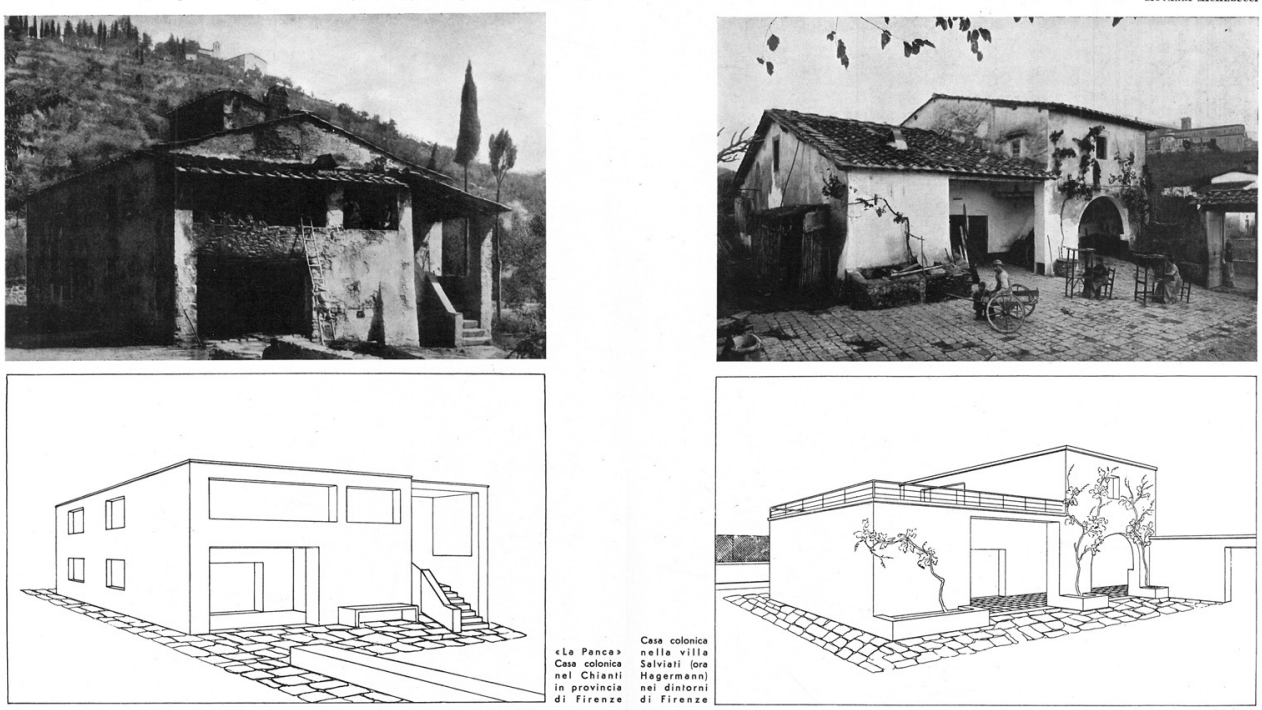

160

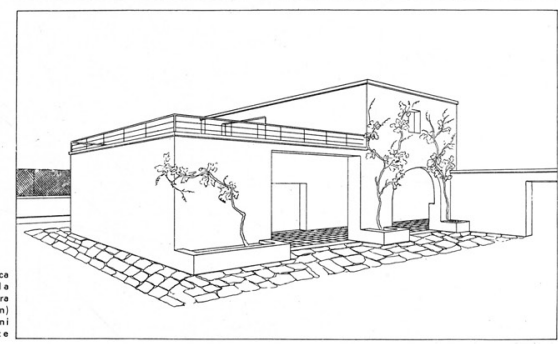

461

cismo. A unque la línea editorial de Quadrante se mantuvo más próxima a una interpretación del racionalismo vinculado a lo clásico, no fue obstáculo para que también publicara artículos cuyo tema central era la arquitectura vernácula mediterránea, lo que constituye una prueba más de la complejidad arquitectónica del momento. Por ejemplo, Luigi Figini ${ }^{56}$ escribió en la revista sobre el Novocomun de Giuseppe Terragni asemejándolo a las arquitecturas tradicionales amalfitanas o de Capri, si bien la posición de Terragni se situaba en esta línea de pensamiento del concepto de mediterraneidad en el sentido clásico-mediterráneo.

U no de los críticos que caracterizaron con mayor precisión el planteamiento de Q uadrante fue Carlo Belli. En un texto muy ilustrativo que envió a Silvia Danesi, narra la atracción que sintió por la arquitectura menor del Sur de I talia tras el viaje que emprendió en 1929 a la península de Salento:

\begin{abstract}
"Telegrafié a Terragni para ponerse en contacto conmigo, pero era un recurso sin esperanza: en aquel tiempo un viaje de Como a Santa M aria di Lèuca era un viaje interplanetario (nuestros "descubrimientos" (iipero los holandeses lo habían hecho yaii) nos lanzan encima la acusación de nórdicos, bolcheviques y antifascistas [... ] El tema de la mediterraneidad y grecità, en la época de la arquitectura racional [... ] eso fue nuestra estrella orientadora [... ]

Estudiamos las casas de Capri: cómo eran construidas, por qué eran hechas de aquel modo. Descubrimos su tradicional autenticidad, y entendimos que su consumada racionalidad coincidía con lo mejor de los valores estéticos. Descubrimos que solamente en el ámbito de la geometría se podía realizar el perfecto consumado gemütlich de vivir"57
\end{abstract}

Resulta especialmente significativo el artículo de Enrico Peressutti que se publicó en Quadrante a principios de 1935 y titulado "A rchitettura M editerranea". Para Peresutti ${ }^{58}$ este término suponía una seña de identidad de una cultura homogénea del M editerráneo que englobaba tanto la arquitectura menor como la arquitectura clásica de Grecia o Roma. Como tantos otros, también se lamentaba al constatar que si bien esta arquitectura vernácula reflejaba la mentalidad moderna arquitectónica, para muchos otros la modernidad era concebida como una novedad de origen nórdico:

“U na herencia que, descubierta por Gropius, Le Corbusier y M ies van der R ohe, fue camuflada como una novedad de origen nórdico, como una invención del siglo XX [... ]Y muchísimos han cogido aquel disfraz por una veraz novedad, para una nueva ley solar. Sin advertir que a aquella novedad faltaba vida, faltaba la palabra, faltaba el canto al M editerráneo"59. 


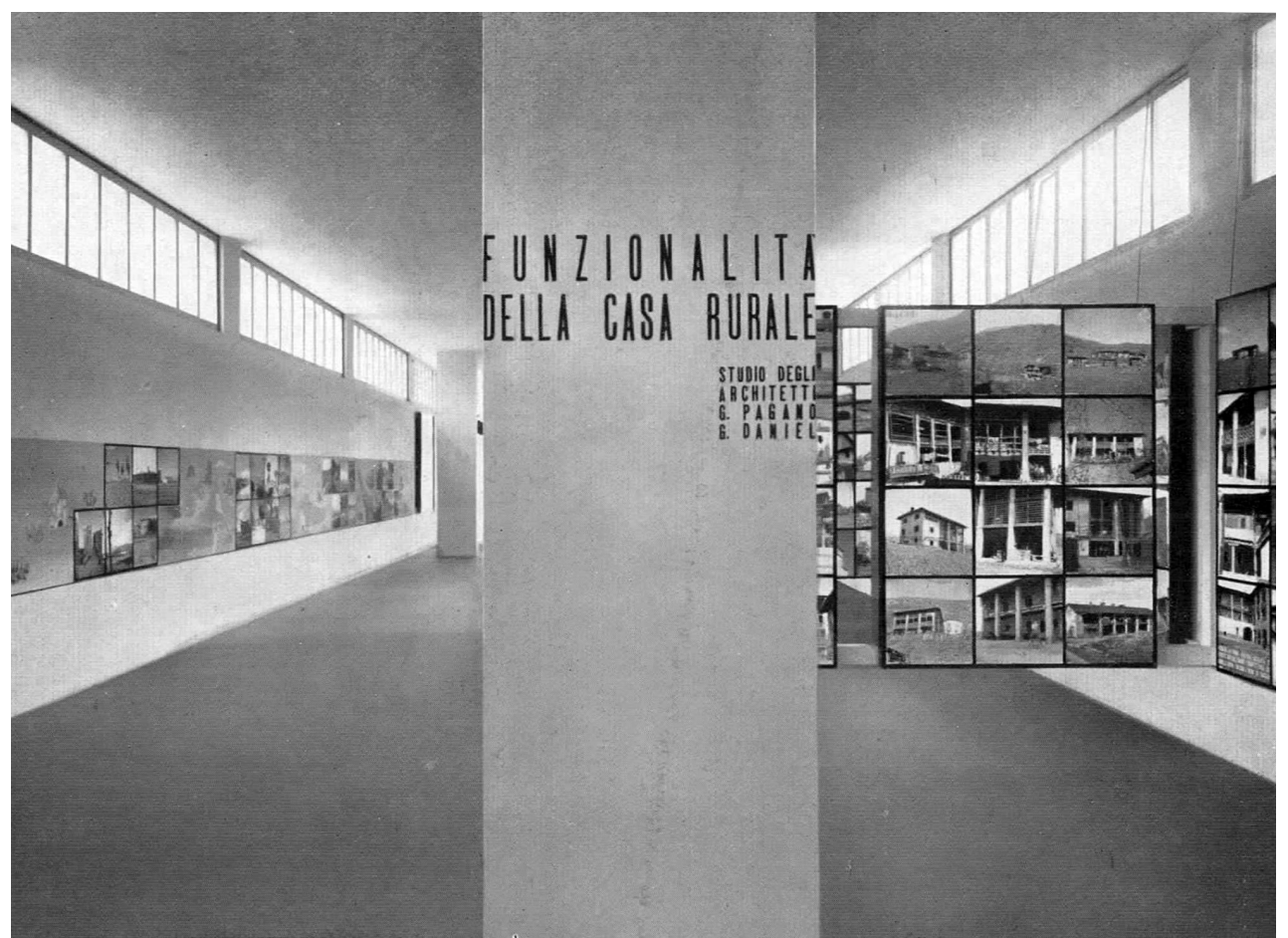

ITALIANOS Y ESPAÑOLES EN EL IV CIAM. CRÓNICAS DE QUADRANTEY AC. DOCUMENTOS DE ACTIVIDAD CONTEMPORÁNEA

Unos meses después de publicarse el primer número de Quadrante, tuvo lugar la celebración del IV CIA M a bordo el Patris II que partió, en agosto de 1933, de M arsella rumbo a A tenas y cuyo tema central se iba a focalizar en la ciudad funcional. La idea del viaje surgió del delegado alemán de la Bauhaus, M arcel B reuer ${ }^{60}$. El discípulo de Gropius y alumno de la B auhaus había visitado España a finales de 1931 y fascinado por los "sencillos y pintorescos pueblos españoles" decidió seguir a Á frica con el objetivo de llegar al origen de dichas arquitecturas ${ }^{61}$.

La presencia española quedó representada con tres arquitectos del GATEPAC, J osep Torres Clavé, J osep L luis Sert y A ntoni B onet, los cuales salieron fortalecidos tras su celebración, como recoge la postal que Torres Clavé envió: "el congreso trabaja duramente. EI equipo español es el amo"62 (Fig. 11).

De Italia viajaron Piero Bottoni, Gino Pollini, Giuseppe Terragni y el director de Q uadrante Pier M aria B ardi. Durante el viaje pudieron contemplar la arquitectura clásica de la A crópolis y la arquitectura vernácula de las islas griegas, sendos paradigmas del carácter mediterráneo, en sintonía con los debates que estaban teniendo lugar en Italia y España. Se escucharon reflexiones y discursos en uno y otro sentido. En la mañana del 3 de agosto, Le Corbusier pronunció su conferencia Air-Son-Lumiére sobre la influencia que la A crópolis "triunfante, infalible, invulnerable" había ejercido en él. En la sesión de la tarde de ese mismo día, A nastasios Orlandos realizó una conferencia que sorprendió a muchos de los participantes del Congreso:

"Cuando, en pocos días, visitéis nuestras alegres islas del Egeo, [...] estoy seguro que quedareis impresionados [... ] Cuando hayáis visto todo aquello, queridos colegas, espero que estéis de acuerdo conmigo que nuestra patria puede jactarse de poseer en estas humildes casas de las islas - aunque no sea sino en germen- los arquetipos de la arquitectura moderna"63.

Los testimonios posteriores dan fe de la importancia que asumió la cuestión de la arquitectura vernácula del M editerráneo en lo que debía ser el Congreso "de la ciudad funcional". Evitar establecer vínculos entre la arquitectura que veían durante el transcurso del viaje y
Fig. 10. Daniel G. y Pagano, G., sala de la Mostra dell'architettura rurale nell bacino del Mediterraneo en la VI Trienal de Milán, 1936, en PODESTA, A., "VI Triennale: Mostre dell'architettura", en Casabella, 1936, 104, p. 11.
60. En el extenso capítulo que la revista $A C$. Documentos de Actividad Contemporánea dedica al congreso encontramos el siguiente párrafo: "Lamentamos igualmente las ausencias de los delegados alemanes Gropius y Breuer, cuyo concurso hubiese sido tan útil al Congreso [...] La dirección envía un telegrama de felicitación a Breuer, feliz iniciador del Congreso a bordo del "Patris II", en AC. DOCUMENTOS DE ACTIVIDAD CONTEMPORÁNEA, "EI IV Congreso del C.I.R.P.A.C. (del 29 de julio al 15 de Agosto de 1933)", en AC. Documentos de actividad contemporánea, 1933, 11, p. 16.

61. LIERNUR, J.F., "Orientalismo y arquitectura moderna: el debate sobre la cubierta plana, en RA: Revista de Arquitectura, 2010, 12, p. 78.

62. RAMÓN GRAELLS, A., RODRÍGUEZ PEDRET, C., "Los viajes de Josep Torres Clavé, 1926-1936. Epistolario, cuadernos de notas y dibujos", en Viajes en la transición de la arquitectura española hacia la modernidad, Congreso internacional de arquitectura moderna española, $7^{\text {a }}$ ed., 6 y 7 de mayo de 2010, Universidad de Navarra, T6) Ediciones, Pamplona, 2010. p. 284.

63. SIMEOFORIDIS, Y., "Dall Athos alle Cicladi: I'scoperta del paesaggio" en Gravagnuolo, B., ed., Le Corbusier e l'antico: viaggi nel Mediterraneo: [mostra], Electa, Nápoles, 1997, p. 56. 
Fig. 11. Delegados españoles del GATEPAC, trabajo de las comisiones y arquitectura vernácula de Seriphos, Grecia, 1933, en AC. DOCUMENTOS DE ACTIVIDAD CONTEMPORÁNEA, "El IV Congreso del C.I.R.P.A.C...", op. cit., pp. 16-17.
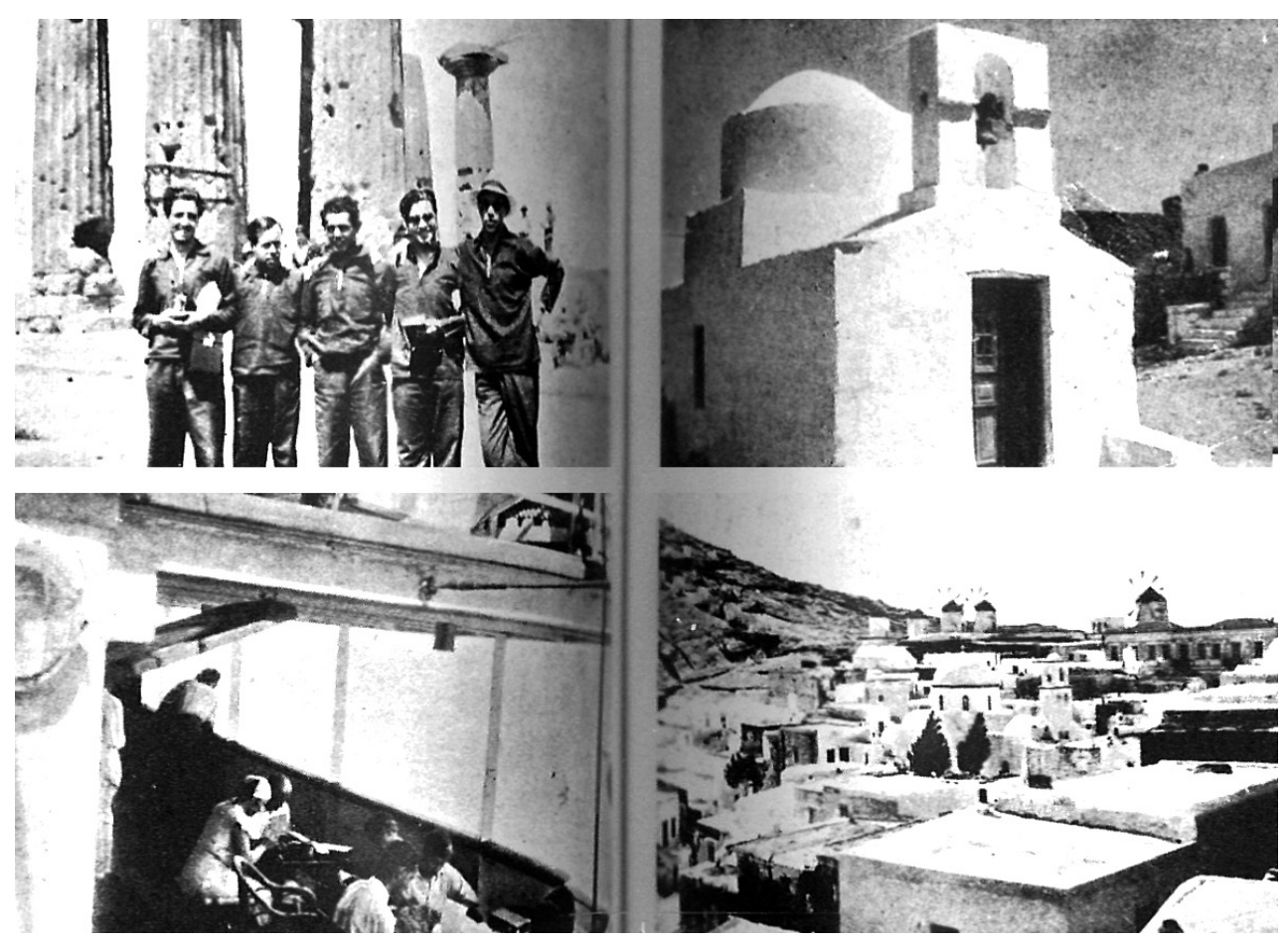

la nueva arquitectura era casi imposible para las revistas Quadrante y AC. D ocumentos de Actividad Contemporánea. En esta úl tima leemos:

\begin{abstract}
"La costa griega y las islas del archipiélago tienen una arquitectura semejante a la de Ibiza y M enorca, pueblos pintados a la cal en blanco o tonos pálidos, tejados planos o abovedados. Es una arquitectura que muy bien podemos considerar como moderna de espíritu, continuación de las mismas formas que se han repetido durante siglos en gran parte de las costas y en todas las islas del mar latino [... ] Los elementos de los grupos latinos tienen en este Congreso mayor importancia que los anteriores; estamos aquí casi en mayoría y navegamos en el M editerráneo [... ] La arquitectura moderna se despierta actual mente a orillas de este mar, o, mejor dicho, se repatrían a sus costas las formas puras de la tradición mediterránea. Estas formas han influido recientemente en las construcciones de los países del Norte, los cuales las han empleado al permitírselo una nueva técnica constructiva" ${ }^{64}$
\end{abstract}

Para Bardi este acontecimiento no pasó desapercibido y se convirtió en un relator más, escribiendo en un tono muy similar al de la revista española:

\footnotetext{
"Desde los primeros días se abrió paso una idea que navega desde hace tiempo: la arquitectura mediterránea, la espera de una arquitectura mediterránea que quede como una afirmación de este siglo englobando y resumiendo el estilo que se busca. Grecia se sumará a la partida, con Italia, Francia, España y África Septentrional"65.
}

En su alegato y defensa de la arquitectura vernácula de las islas escribió que: "Las casitas agradables y con las pequeñas ventanas tienen la misma mano de blanco, de rosa, o de azul [... ] la arquitectura está en la sangre de la tradición. La casa nace en el M editerráneo [... ] en estos pueblecitos no hay arquitectos, porque todos los constructores son arquitectos"66 (Fig. 12).

Pollini ${ }^{67}$ fue el encargado de cerrar el generoso artículo que Quadrante dedicó al IV

64. AC. DOCUMENTOS DE ACTIVIDAD CONTEMPORÁNEA, "El IV Congreso del C.I.R.P.A.C...", cit. p. 17.

65. BARDI, P.M., "Cronaca di viaggio", en Quadrante, 1933, 5, p. 13.

66. Ibid. p. 19.

67. POLLINI, G., "Corsivo n. 40" en Quadrante, 5, 1933, p. 35 68. POLLINI, G., op. cit. p. 47.

69. AC. DOCUMENTOS DE ACTIVIDAD CONTEMPORÁNEA

"La exposición de 'La Triennale'-Milán”, en AC. Documentos de Actividad Contemporánea, 1934, 13, p. 38.
Congreso en el "Corsivo n. 40". En el mismo número de la revista, Pollini68 reflexionaba sobre el patio como un "concepto" cuyo espíritu podría servir como elemento diferenciador en los desarrollos de la arquitectura funcional. Coincidía con la revista A.C. D ocumentos de Actividad Contemporánea en destacar este el emento característico de la tradición mediterránea: "Dicho concepto [... ] podrá revivir actual mente y contar como elemento característico diferenciador de la arquitectura funcional mediterránea de la nórdica" 69 .

Las referencias cruzadas entre ambos países surgieron con mayor intensidad tras la celebración del congreso, sobre todo desde la revista A.C. D ocumentos de Actividad Contem- 


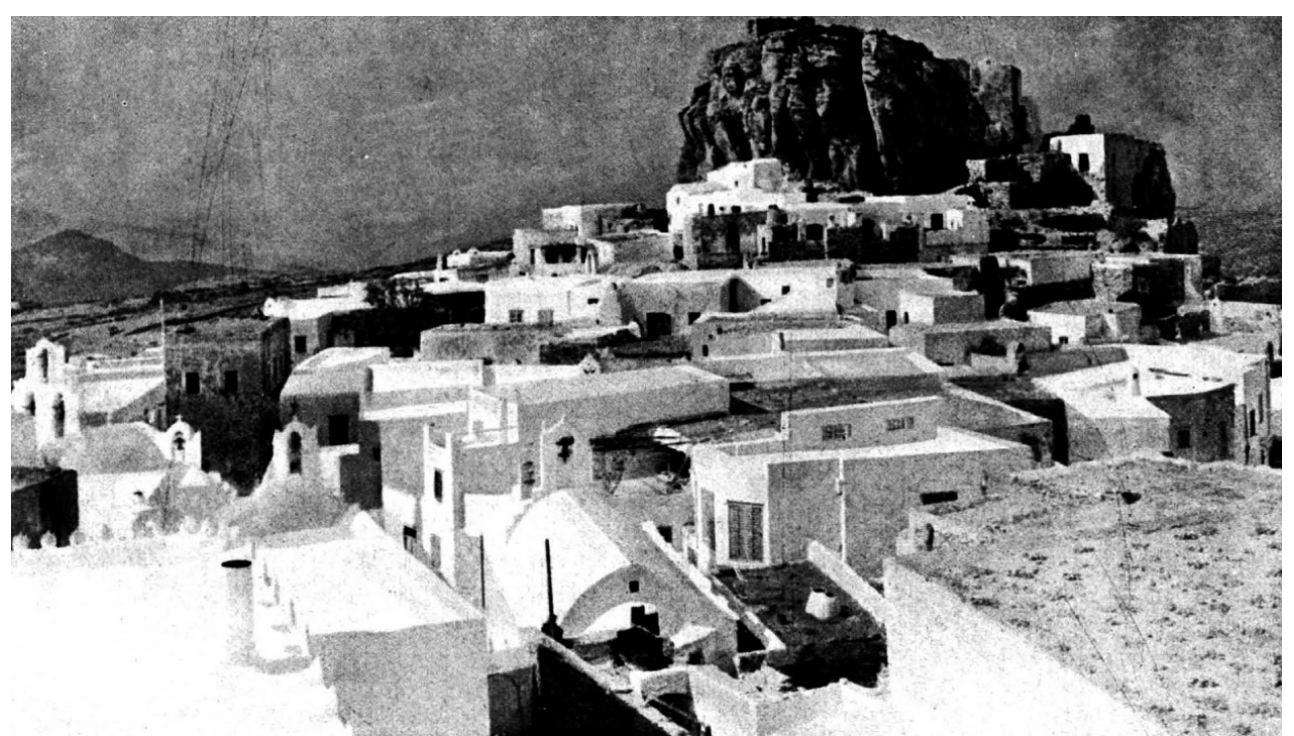

12

poránea que publicó algunos artículos relacionados con la realidad arquitectónica italiana. Se presentaron los proyectos para la Triennale de M ilán como una arquitectura con un denominador común de "latinidad" y "meridionalidad" que los distinguían de los arquitectos nórdicos ${ }^{70}$.

En el número 13 de A.C. Documentos de Actividad Contemporánea se expuso la "ViIla estudio para un artista" de G. Pollini y Figini como "una de las mejores obras italianas de la arquitectura moderna; de una gracia y atractivo exclusivamente mediterráneo". La arquitectura italiana era presentada como un ejemplo contra el estilo Imperium Romanum, el clasicismo modernizado, el pseudo-moderno: "la arquitectura moderna triunfa en Italia, como triunfará en todas partes"71.

Un año más tarde, el arquitecto griego Panos Djelepy publicaba en la revista Cahiers d'Art de Christian Zervos, también presente en el congreso, un artículo titulado "Les maisons de l'archipel grec. Observées du point de vue de l'architecture moderne" donde se refirió explícitamente al interés que despertaba esta cuestión en los congresistas de A tenas (Fig. 13).

El propio Le Corbusier ${ }^{72}$ escribía en 1935 su experiencia del IV CIAM en uno de los textos de La Ville Radieuse. No obstante, su contribución con la conocida "Teoría de los Ejes" fue una de aportaciones más interesantes del congreso y sobre la que el propio Bardi73 especuló acerca del interés del maestro suizo por alinearse junto al Duce para conseguir diversos encargos en I tali ia ${ }^{74}$.

\section{CONCLUSIÓN}

En el artículo hemos analizado las consecuencias de la internacionalización de la arquitectura moderna desde los países centroeuropeos y su influencia particular en las regiones del ámbito mediterráneo. Si bien en Italia las primeras posturas por parte de las vanguardias - Gruppo Sette- asumían términos como "romanidad", "latinidad" o "classicità" en un contexto marcado por el Régimen fascista, en España lo "vernáculo" era asumido prácticamente desde el principio como única opción por la generación del 25 debido en parte a la formación recibida desde el ámbito universitario.

En ambos contextos constatamos prácticamente desde el principio y coincidente en el tiempo, intensos debates sostenidos en el seno de las vanguardias mediterráneas sobre el origen y fundamentos de la arquitectura moderna debido a la existencia de una arquitectura vernácula que era comparada con la arquitectura moderna procedente de Centroeuropa. L a comparación se realizaba atendiendo a criterios formales derivados de los principios de

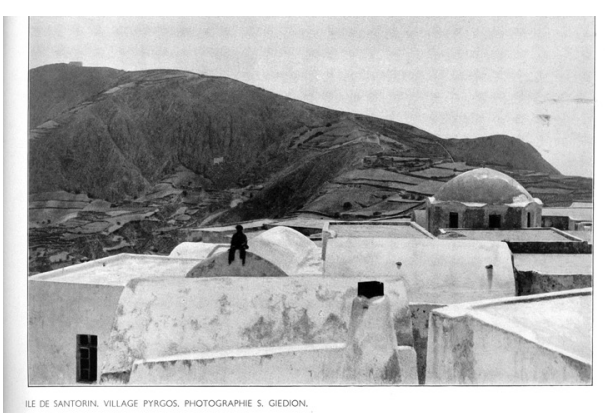

LES MAISONS DE L'ARCHIPEL GREC OBSERVÉES DU POINT DE VUE DE L'ARCHITECTURE MODERNE

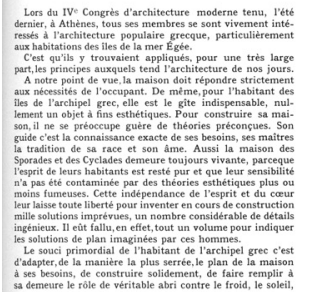

13

Fig. 12. Vista de Amorgos desde la Acrópolis, en BARDI, P.M., "Cronaca di viaggio", op. cit., p. 27.

Fig. 13. Djelepy, artículo sobre la arquitectura vernácula de las islas Santorini, Mikonos y Siphnos, en DJELEPY, P., "Les Maisons de L'Archipel Grec. Observées du point de vue de l'architecture moderne", en Cahiers d'Art, 1934, 1-4, p. 93.

70. Hasta ese momento las referencias al racionalismo italiano habían aparecido en el número 5 de la revista $A C$. Documentos de Actividad Contemporánea, pero en ningún caso mencionaban vinculación alguna con la arquitectura vernácula mediterránea o los conceptos de "latinidad", "romanidad" 0 "mediterraneidad".

71. AC. DOCUMENTOS DE ACTIVIDAD CONTEMPORÁNEA, “La exposición de 'La Triennale'-Milán”, cit. p. 40.

72. LE CORBUSIER, La ville radieuse: éléments d'une doctrine d'urbanisme pour l'équipement de la civilisation machiniste, Vincent Fréal et Cie, París, [1935] 1964.

73. BARDI, P. M., "Cronaca di viaggio", cit. p. 19.

74. Nos referimos al encargo del Agro Pontino y los posteriores trabajos de urbanización de la periferia de Roma, Olivetti y Volpi, en LE CORBUSIER, op, cit. p. 329 y DANESI, S., op. cit. p. 25. 
funcionalidad, racionalismo u objetividad. Estos conceptos, por otra parte institucionalizados en los discursos de la vanguardia moderna europea, eran reconocidos en la arquitectura vernácula, lo cual les animaba a crear una arquitectura moderna propia.

Las reacciones que este fenómeno suscitó en el ámbito mediterráneo es la prueba evidente de que estamos ante un contexto de desconcierto evidente en la búsqueda de un lenguaje arquitectónico moderno propiamente mediterráneo del que se consideraban legítimos herederos.

Si tuviéramos que establecer un punto en común entre las posiciones asumidas acerca de los distintos debates en los contextos español e italiano, podríamos fijarlo en el espacio común que ambas ocuparon entre la modernidad y la tradición.

Pedro Miguel Jiménez Vicario. Doctor Arquitecto, es miembro del Departamento de Arquitectura y Tecnología de la Edificación y profesor en la Escuela Técnica Superior de Arquitectura y Edificación de la Universidad Politécnica de Cartagena. Sus investigaciones se centran en el estudio del Movimiento Moderno y la arquitectura vernácula del Mediterráneo. Sus trabajos al respecto han sido publicados en diversas revistas y congresos internacionales, además de ser autor de varios libros. Desarrolla actividades de innovación docente y pertenece a diversas comisiones y tribunales de evaluación. Ha sido comisario de exposiciones de pintura y arquitectura y ha expuesto su obra en varias de ellas.

Micaela Antonucci. Doctora Arquitecta. Es profesora del Dipartimento di Architettura dell'Università di Bologna y miembro del Collegio del Dottorato di Ricerca in Architettura dell'Università di Bologna. Ha estado a cargo de la investigación y los proyectos científicos nacionales e internacionales centrados en la historia de la arquitectura y técnicas de construcción y conservación, así como de la mejora del patrimonio artístico y arquitectónico, documentada por numerosas publicaciones y eventos (conferencias, exposiciones, etc.). Sus investigaciones se centran en la arquitectura del Renacimiento en Italia y sobre arquitectura contemporánea en Italia y en Europa, con estudios monográficos sobre Antonio da Sangallo il Giovane, Otto Wagner y Pier Luigi Nervi. 